\title{
LiSAF: AN EFFICIENT AND DURABLE NONLINEAR MATERIAL FOR SUPERCONTINUUM GENERATION IN THE ULTRAVIOLET
}

\author{
A. Šuminienė, V. Jukna, R. Šuminas, G. Tamošauskas, M. Vengris, and A. Dubietis \\ Laser Research Center, Vilnius University, Sauletekio 10, 10223 Vilnius, Lithuania \\ Email: audrius.dubietis@ff.vu.lt
}

Received 9 September 2020; accepted 11 September 2020

\begin{abstract}
We have experimentally studied supercontinuum generation in an undoped LiSAF crystal using ultraviolet, visible and near infrared pump pulses provided by fundamental and second harmonics of amplified femtosecond Ti:sapphire and $\mathrm{Yb}: \mathrm{KGW}$ lasers. We have found that the optical degradation of the crystal, manifested by gradual narrowing of the supercontinuum spectrum, starts much faster using infrared pump pulses. This is attributed to the role of impact ionization, which increases with increasing the pump wavelength. The most reliable operation is achieved with the shortest pump wavelength of $400 \mathrm{~nm}$ (the second harmonic of a Ti:sapphire laser), where LiSAF produces a stable, almost 1.3 octave-spanning supercontinuum spectrum with a short-wavelength cut-off at $252 \mathrm{~nm}$ and shows no apparent optical degradation for one hour of continuous operation at $500 \mathrm{~Hz}$ repetition rate without crystal translation.
\end{abstract}

Keywords: supercontinuum generation, femtosecond filamentation, ultraviolet

PACS: 42.65.Re, 42.65.Jx, 42.70.-a

\section{Introduction}

Ultraviolet (UV) is a highly desired spectral region for studies of the electronically excited state dynamics by means of time-resolved spectroscopy using a supercontinuum (SC) probe (see, e.g. Refs. [1-3]). It is especially important in the research of biological materials, such as proteins [4] and DNA [5], as well as wide bandgap semiconductors [6]. However, SC generation in this spectral region is a difficult task because of stringent limiting physical factors and lack of suitable nonlinear materials (see, e.g. Refs. [7, 8]). Spectral broadening toward shorter wavelengths is constrained by low order nonlinear absorption [9] as well as by large material dispersion [10], which rapidly increases toward higher frequencies. As a result, filamentation of UV laser pulses in wide bandgap solid-state dielectric media produces only a modest spectral broadening and so relatively narrow SC spectra [1]. Moreover, due to large incident photon energy all materials are prone to rapid optical degradation and, eventually, to optical damage.

Therefore, a more convenient and widely used approach is to use pump wavelengths located in the visible or near IR spectral range. Experiments show that filamentation in alkali metal fluorides, such as $\mathrm{LiF}, \mathrm{CaF}_{2}, \mathrm{MgF}_{2}$ and $\mathrm{BaF}_{2}$, produces SC spectra with the largest blue shifts [12-15, extending below $300 \mathrm{~nm}$. Typical SC spectra in these materials are considerably broader as compared to these attainable in YAG and sapphire, that are widely used nonlinear crystals for SC generation and show a superior performance in the visible and near IR [16-18]. However, the nonlinear materials that produce the largest spectral blue shifts, $\mathrm{LiF}$ and $\mathrm{CaF}_{2}$, exhibit several drawbacks that are unattractive for practical applications. More 
specifically, $\mathrm{LiF}$ is prone to rapid formation of colour centres, which modify the SC spectrum to a certain degree $[19,20]$. On the other hand, optical damage in $\mathrm{CaF}_{2}$ due to heat accumulation develops very quickly even at relatively low $(1 \mathrm{kHz})$ pulse repetition rate, so the crystal should be continuously translated [21].

The above difficulties motivate further search of suitable nonlinear materials for SC generation in the UV. One of potentially attractive candidates is lithium strontium hexafluoroaluminate ( $\mathrm{LiSrAlF}_{6}$, LiSAF). LiSAF is a well-known laser host crystal that could be doped with transition metal and rare earth ions. Chromium doped LiSAF crystal serves as an excellent laser material that allows tunable lasing in the near IR [22] and produces femtosecond pulses in that wavelength region[23], while doped with cerium, LiSAF becomes an attractive UV solid-state laser material, which affords wavelength tunability in the $280-320 \mathrm{~nm}$ range [24]. The latter application indirectly suggests that the LiSAF crystal itself is highly resistable to intense UV irradiation. In addition to that, LiSAF exhibits an excellent set of optical properties: a very large energy bandgap of $11.79 \mathrm{eV}$ [25], a shortwavelength absorption edge at $116 \mathrm{~nm}$ [26], a low refractive index and so a low chromatic dispersion throughout the UV, visible and near IR, that qualify this crystal as a potentially attractive material for SC generation.

In this paper, we present the experimental results that fully confirm the above presumption. We show that the femtosecond filamentation in undoped LiSAF produces SC with a large spectral blue shift that extends into the deep UV. Moreover, our results demonstrate that the LiSAF crystal shows durable operation without its translation at $500 \mathrm{~Hz}$ repetition rate, when being pumped by ultraviolet femtosecond laser pulses.

\section{Experimental results}

We performed a series of experiments using fundamental and second harmonics from commercial amplified Ti:sapphire (Spitfire-PRO, NewportSpectra Physics, pulse repetition rate $500 \mathrm{~Hz}$ ) and Yb:KGW (Pharos, Light Conversion Ltd., pulse repetition rate $1 \mathrm{kHz}$ ) lasers.

The second harmonics from both lasers were generated using a $1 \mathrm{~mm}$-thick $\mathrm{BBO}$ crystal cut for type I phase matching. In each experiment, the pump beam was focused by means of $\mathrm{a} \mathrm{BaF}_{2}$ lens $(f=+100 \mathrm{~mm})$ onto the input face of a $5 \mathrm{~mm}$ thick undoped and uncoated LiSAF crystal (Optogama), which was not translated during the measurement. The energies of pump pulses were set to produce a single filament and stable SC spectrum at the output, which does not broaden anymore with further increase of the energy. Relatively large energy values were required to achieve such operating condition because of a very small nonlinear refractive index of LiSAF, $n_{2}=1.18 \cdot 10^{-}$ ${ }^{16} \mathrm{~cm}^{2} / \mathrm{W}$ at $532 \mathrm{~nm}$ and $n_{2}=0.52 \cdot 10^{-16} \mathrm{~cm}^{2} / \mathrm{W}$ at $1064 \mathrm{~nm}$ [27]. The relevant experimental parameters of the pump pulses at each wavelength are summarized in Table 1.

The SC spectra were measured using a fibre spectrometer (Avantes AvaSpec-3648), which provides a detection range from 200 to $1100 \mathrm{~nm}$. In order to increase the dynamic range of spectral measurements, the most intense parts of the SC spectra (those around the respective pump wavelengths) were attenuated using appropriate combinations of highly reflective mirrors and colour filters. Thereafter the measured spectra were corrected for the individual mirror and filter transmittance functions and the sensitivity function of the spectrometer detector.

Figure 1 presents the SC spectra produced with all four pump wavelengths. All the measured SC spectra show more than octave-spanning bandwidths and quite remarkable blue shifts into the UV. The largest blue shifts of the SC spectra were produced using the second harmonic pulses from both lasers; the SC spectra on the shortwavelength side extend into the deep UV, down to 252 and $260 \mathrm{~nm}$ as measured with 400 and $515 \mathrm{~nm}$ pump pulses, respectively. The measured

Table 1. Summary of the pump pulse parameters $\lambda_{\mathrm{p}}, \tau_{\mathrm{p}}, E_{\mathrm{p}}$ and $d_{\mathrm{in}}$, which stand for the wavelength, pulsewidth, energy and FWHM beam diameter at the input face of the crystal, respectively. $\lambda_{\mathrm{UV}}$ is the detected UV cut-off wavelength of the SC spectrum.

\begin{tabular}{r|r|r|c|c}
\hline$\lambda_{\mathrm{p}}, \mu \mathrm{m}$ & $\tau_{\mathrm{p}}, \mathrm{fs}$ & $E_{\mathrm{p}}, \mu \mathrm{J}$ & $d_{\mathrm{in}}, \mu \mathrm{m}$ & $\lambda_{\mathrm{UV}}, \mu \mathrm{m}$ \\
\hline 400 & 120 & 0.6 & 45 & 252 \\
\hline 515 & 220 & 2.0 & 35 & 260 \\
\hline 800 & 120 & 1.8 & 45 & 330 \\
\hline 1030 & 330 & 10 & 50 & 335 \\
\hline
\end{tabular}




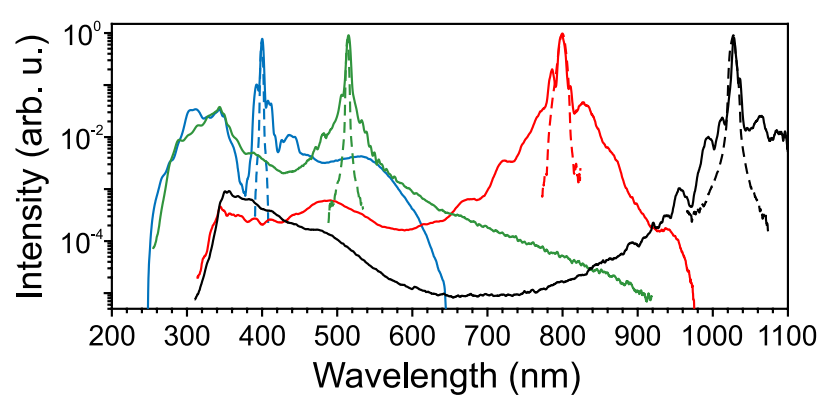

Fig. 1. Supercontinuum spectra generated in LiSAF using pump pulses with carrier wavelengths of $1030 \mathrm{~nm}$ (black curve), $800 \mathrm{~nm}$ (red (online) curve), $515 \mathrm{~nm}$ (green (online) curve) and $400 \mathrm{~nm}$ (blue (online) curve). The respective spectra of the input pulses are depicted by dashed curves.

UV cutoff wavelengths (defined at the $10^{-4}$ intensity level) are listed in Table 1. The absolute blue shifts (estimated as the differences between the pump and the shortest generated wavelength) increase with increasing the pump wavelength, which changes the conditions of nonlinear propagation from four-photon absorption at $400 \mathrm{~nm}$ to ten-photon absorption at $1030 \mathrm{~nm}$. This is very much in line with general experimental findings that highlight the role of the order of multiphoton absorption, suggesting the broadest blue shifts attained in the conditions of high order multiphoton absorption [9].

From a practical point of view, the main issue concerning SC generation in the UV is degradation of the nonlinear material due to formation of colour centres and/or evolving structural modifications, which cause gradual extinction of the SC spectrum over time. In order to examine the reproducibility of the SC spectra, we investigated spectral dynamics of the blue-shifted portions of the SC spectra as functions of exposure time. Figure 2 compares the UV parts of initial SC spectra (integrated over $1 \mathrm{~ms}$ corresponding to few tens of laser shots) and those recorded after 1 and $10 \mathrm{~min}$ of exposure time, using pump pulses with wavelengths of 1030, 800, 515 and $400 \mathrm{~nm}$. After $1 \mathrm{~min}$ of exposure, only very slight changes in the UV parts of the SC spectra (narrowing by $1 \mathrm{~nm}$ ) are observed with 400, 515 and $800 \mathrm{~nm}$ pumping, while the UV part of the SC spectrum produced with $1030 \mathrm{~nm}$ pump pulses shrinks more considerably (by $10 \mathrm{~nm}$ ). After $10 \mathrm{~min}$ of exposure, the changes in the UV spectra (spectral shrinking along with a significant decrease of (a)

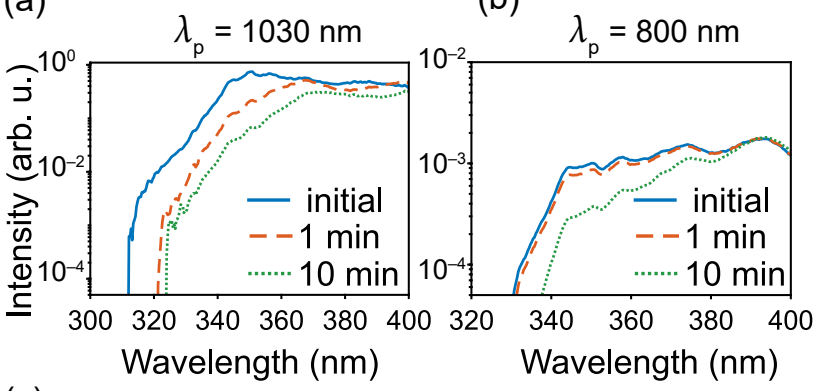

(c)

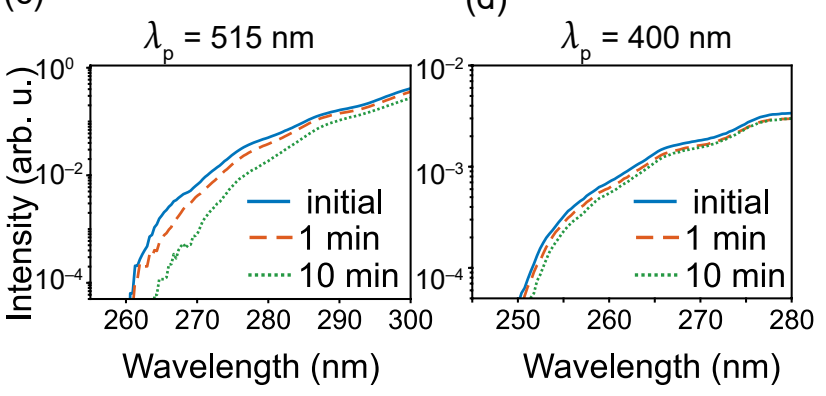

Fig. 2. Changes in the UV parts of supercontinuum spectra produced with (a) $1030 \mathrm{~nm}$, (b) $800 \mathrm{~nm}$, (c) $515 \mathrm{~nm}$ and (d) $400 \mathrm{~nm}$ pump pulses after exposure times of 1 and $10 \mathrm{~min}$.

the spectral intensity) become apparent with 515 and $800 \mathrm{~nm}$ pumping as well, while the changes in the UV part of the SC spectrum produced by $400 \mathrm{~nm}$ pump pulses still remain barely noticeable. It is quite surprising that the most stable and reproducible UV part of the SC spectrum is generated with the pump pulses having the shortest wavelength (400 $\mathrm{nm}$ ).

This feature is highlighted in more detail by presenting dynamics of a short wavelength portion of the SC spectrum versus the exposure time on a longer time scale $(1 \mathrm{~h})$ for pump wavelengths of 1030 and $400 \mathrm{~nm}$ in Fig. 3. A gradual narrowing of the SC spectrum is clearly observed with $1030 \mathrm{~nm}$ pumping. A ragged edge of the plot in Fig. 3(a) also indicates a considerable decrease of the SC stability throughout the visible and UV spectral ranges. For instance, the standard deviation of SC intensity at $360 \mathrm{~nm}$ always keeps around $15 \%$, while at $450 \mathrm{~nm}$, the standard deviation increases from $1 \%$ initially to $9.6 \%$ measured after $1 \mathrm{~h}$. In contrast, spectral measurements with pump pulses at $400 \mathrm{~nm}$ confirm a robust performance of the crystal during $1 \mathrm{~h}$ of operation, as justified by the data presented in Fig. 3 (b).

In addition, we experimentally tested lithium calcium hexafluoroaluminate ( $\left.\mathrm{LiCaAlF}_{6}, \mathrm{LiCAF}\right)$ 


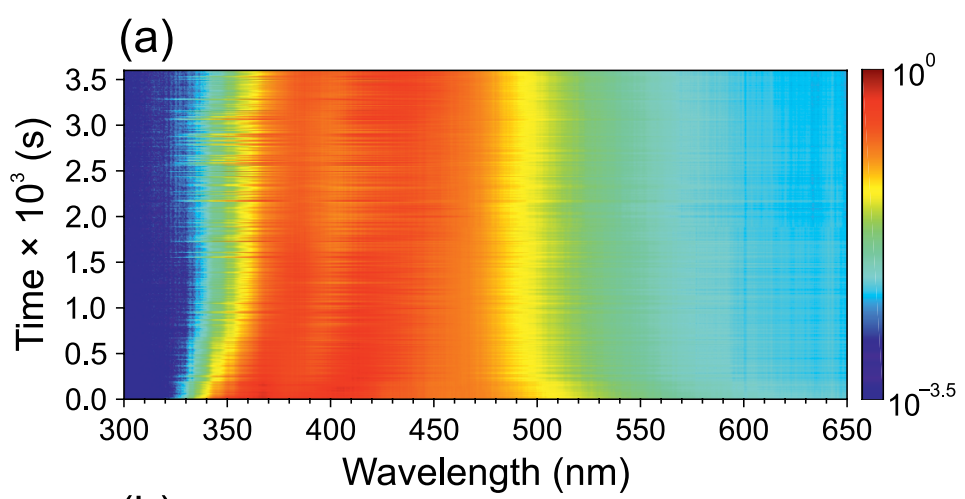

(b)

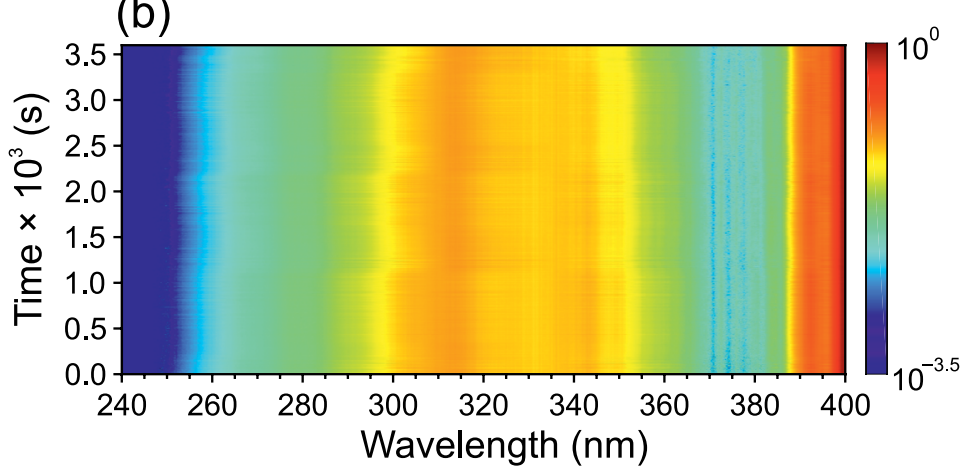

Fig. 3. Spectral dynamics of a short wavelength part of the SC spectrum over $1 \mathrm{~h}$ of operation in an untranslated crystal measured with: (a) $1030 \mathrm{~nm}$, (b) $400 \mathrm{~nm}$ pump pulses.

crystal, which has very similar optical characteristics as LiSAF, and exhibits a slightly larger energy bandgap (12.23 eV [25]) and somewhat better transparency in the UV, with a short-wavelength absorption edge at $112 \mathrm{~nm}$ [26]. Figure 4 presents the SC spectra generated in the $5 \mathrm{~mm}$-long LiCAF sample (Optogama) using the pump beams with parameters listed in Table 1. The SC spectra and their UV cut-off wavelengths produced in LiCAF are very similar to those measured in LiSAF (see Fig. 1), and the same tendency of optical degrada-

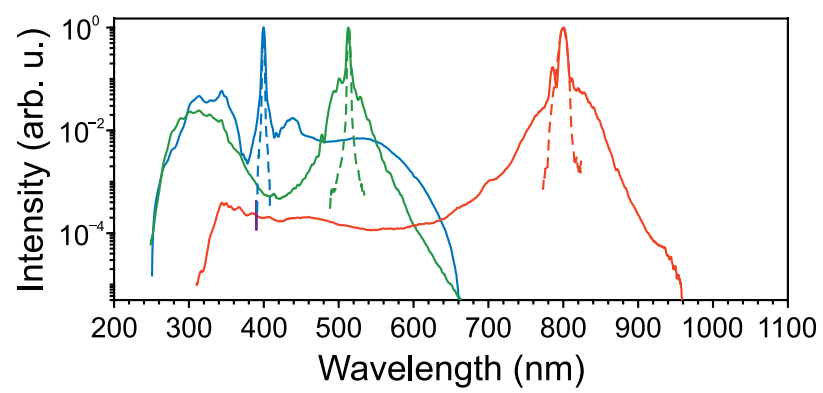

Fig. 4. Supercontinuum spectra generated in LiCAF using pump pulses with carrier wavelengths of $800 \mathrm{~nm}$ (red (online) curve), $515 \mathrm{~nm}$ (green (online) curve) and $400 \mathrm{~nm}$ (blue (online) curve). The respective spectra of the input pulses are depicted by dashed curves. tion of the crystal versus pump wavelength was observed. However, the LiCAF crystal does not possess the durability of LiSAF. The optical degradation of LiCAF starts very fast, as justified by gradual narrowing of the SC spectrum. Using $1030 \mathrm{~nm}$ pump pulses, optical degradation of the crystal was so fast that it was almost impossible to record an unaffected SC spectrum, therefore it is not presented in Fig. 4. The most durable performance was recorded with $400 \mathrm{~nm}$ pump pulses; however, even in this case, stable SC generation was observed just for 5 min of continuous operation.

Summarizing the experimental observations, the longer the pump wavelength is, the faster and more noticeable narrowing of the SC spectrum is observed. This narrowing behaviour is characteristic, and is related to optical degradation of the crystal, despite the differences in relevant parameters of the pump pulses produced by Ti:sapphire and $\mathrm{Yb}: \mathrm{KGW}$ lasers: pulse repetition rate, pulsewidth and energy. Since we investigated just the early stage of optical degradation, the visual inspection of both crystals did not reveal any noticeable changes of their optical quality in the bulk, e.g. coloration, scattering of light, etc. 


\section{Discussion}

Although the observed wavelength dependence of optical degradation may seem quite surprising, we explain this feature considering two relevant factors. Firstly, beam filamentation and SC generation with a longer wavelength requires higher power (energy) of the pump pulses. This is according to the definition of the critical power for self-focusing, that is proportional to the square of the incident wavelength $\lambda: P_{\mathrm{cr}}=3.77 \lambda_{\mathrm{p}}^{2} / 8 \pi n_{0} n_{2}$, where $n_{0}$ and $n_{2}$ are linear and nonlinear indexes of refraction, respectively. The catastrophic collapse of a self-focusing pump beam is stopped by the nonlinear absorption (multiphoton absorption, impact ionization), which produces free electron plasma. Free electron plasma has a defocusing effect that, combined with diffraction, limits the minimum beam diameter at the nonlinear focus and so clamps the intensity to a certain level (see, e.g. Ref. [8]). For a longer pump wavelength, a larger number of photons for the electron to overcome the bandgap of the material is needed due to lower photon energy. The larger the order of multiphoton absorption $(K=\langle U / \hbar \omega\rangle+1)$ is, where $\hbar \omega$ is the photon energy, or in other words, the larger the number of photons is needed to free an electron, the lower the multiphoton ionization probability, that was calculated using the model presented in Ref. [28] and is illustrated in Fig. 5. In the present case, assuming the energy bandgap of LiSAF crystal of $U_{\mathrm{g}}=11.79 \mathrm{eV}, 4,5,8$ and 10 photons are re- quired to transfer an electron from the valence to conduction band of the crystal, using pump pulses with wavelengths of 400, 515, 800 and $1030 \mathrm{~nm}$, respectively.

Secondly, the impact ionization is an important effect in the process of free electron generation. The contribution of impact ionization in the plasma generation process increases for longer wavelength pulses and becomes very important. The free electrons generated by multiphoton absorption/ionization acquire the necessary energy to initiate impact ionization via inverse bremsstrahlung effect. Figure 5 shows the calculated inverse bremsstrahlung cross section $\sigma$ versus wavelength for LiSAF taking the electron collision time of $3 \mathrm{fs}$. Notably, the inverse bremsstrahlung cross section is almost 7 times larger for infrared $(1030 \mathrm{~nm})$ than for ultraviolet $(400 \mathrm{~nm})$ pump pulses. For the impact ionization to occur, an electron needs to acquire energy exceeding the energy bandgap $U_{\mathrm{g}}$ of the material by roughly a factor of 1.5 [29], where a fraction of acquired energy is used for interaction with phonons and is responsible for local heating. That means that there is a distribution of electron energies, and a fraction of them are involved in the impact ionization process. Therefore, when the impact ionization is responsible for generating a considerable number of free electrons, the average electron energy is higher compared to the process when only multiphoton absorption/ ionization is dominant.

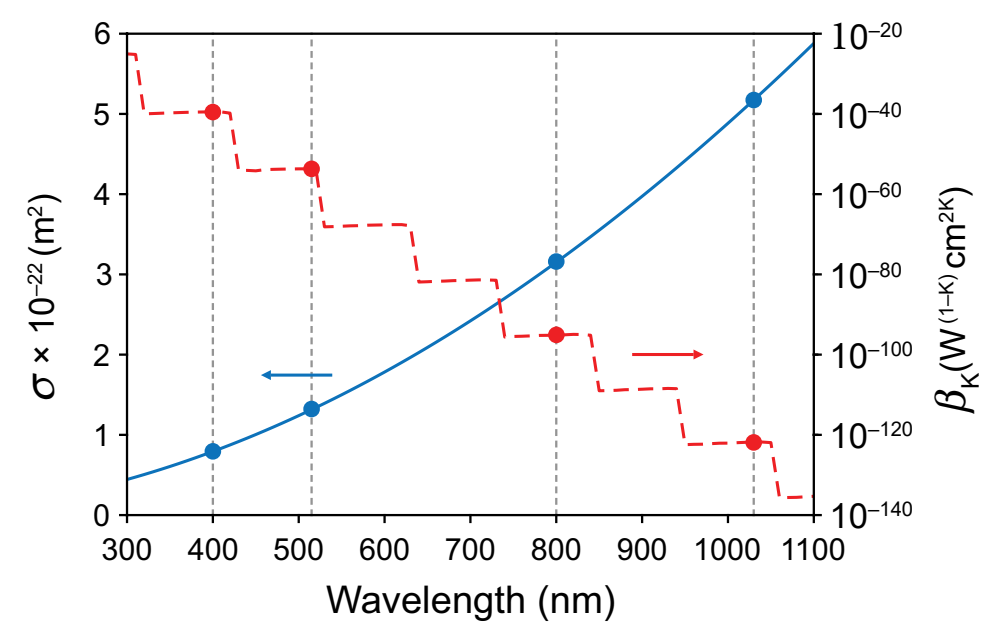

Fig. 5. Inverse bremsstrahlung cross section $\sigma$ and multiphoton ionization coefficient $\beta_{\mathrm{K}}$ of LiSAF as functions of laser wavelength calculated taking the electron collision time of $3 \mathrm{fs}$. Bold dots denote the laser wavelengths used in the experiment. 
Considering the above, for the infrared pulses, the intensity is clamped to a higher value, since fewer free electrons are produced by multiphoton absorption/ionization. Thereafter these electrons are efficiently accelerated by the inverse bremsstrahlung effect and acquire sufficient energy to initiate the process of impact ionization and further multiplication of free electrons via the avalanche ionization process. When free electron plasma recombines, electrons lose their energy through the luminescence and material heating, the higher energy electrons induce larger temperature increase of the material, that potentially leads to local structural modification (or optical degradation) of the material. In contrast, for the UV pulses, free electrons are mainly produced by multiphoton absorption/ionization. Their acceleration via inverse bremsstrahlung effect is less efficient, therefore, as a result, less local heating of the material is produced with the same amount of free electrons. This in turn suggests that the structural modifications leading to optical degradation of the material evolve more slowly.

Although the wavelength dependence of free electron generation via the multiphoton and impact ionization processes and their balance is more complex [30], the general trend is very similar as described above. The balance between the numbers of free electrons generated via multiphoton absorption/ionization and avalanche ionization also depends on the pulse duration. Longer pulses produce a larger number of photons by impact ionization that favours further generation of free electrons via the avalanche ionization process. As for the differences of robustness observed between different materials with near-identical optical properties, their origin remains unclear. The described interplay of multiphoton ionization and impact ionization is a general mechanism, valid for any material. The reasons of different reaction of LiSAF and LiCAF would have to lie in the differences in the formation of impurities and the impact ionization cross-sections, as well as the presence of intrinsic lattice defects. Further investigation is needed to shed light on this issue.

\section{Conclusions}

In conclusion, we demonstrated that the LiSAF crystal serves as an efficient and durable nonlin- ear material for SC generation in the UV spectral range. In particular, using the second harmonic of a Ti:sapphire laser, we achieved stable SC generation for $1 \mathrm{~h}$ of operation at $500 \mathrm{~Hz}$ repetition rate without crystal translation, producing almost a 1.3 octave-spanning SC spectrum with a short-wavelength cut-off at $252 \mathrm{~nm}$. The experiments performed with fundamental and second harmonic pulses from Ti:sapphire and $\mathrm{Yb}: \mathrm{KGW}$ femtosecond lasers revealed that narrowing of the SC spectrum, which is related to optical degradation of the crystal, started much faster when a longer pump wavelength was used. This feature is explained in part by quadratic wavelength dependence of the critical power for self-focusing, and mainly by the contribution of impact ionization, which is most efficient for laser pulses with a longer wavelength. Very similar SC spectra and their narrowing tendencies were recorded in the LiCAF crystal that, however, showed much faster optical degradation and poorer performance on a long term scale.

\section{Acknowledgements}

The authors acknowledge financial support from the European Regional Development Fund (ERDF), Grant No. 1.2.2-LMT-K-718-02-0017.

\section{References}

[1] U. Megerle, I. Pugliesi, C. Schriever, C.F. Sailer, and E. Riedle, Sub-50 fs broadband absorption spectroscopy with tunable excitation: putting the analysis of ultrafast molecular dynamics on solid ground, Appl. Phys. B 96, 215-231 (2009).

[2] E. Riedle, M. Bradler, M. Wenninger, C.F. Sailer, and I. Pugliesi, Electronic transient spectroscopy from the deep UV to the NIR: unambiguous disentanglement of complex processes, Faraday Discuss. 163, 139-158 (2013).

[3] N. Krebs, I. Pugliesi, J. Hauer, and E. Riedle, Twodimensional Fourier transform spectroscopy in the ultraviolet with sub-20 fs pump pulses and $250-720 \mathrm{~nm}$ super-continuum probe, New J. Phys. 15, 085016 (2013).

[4] S. Schenkl, F. van Mourik, G. van der Zwan, S. Haacke, and M. Chergui, Probing the ultrafast charge translocation of photoexcited retinal in bacteriorhodopsin, Science 309, 917-920 (2005). 
[5] T.Fiebig, M.Chachisvilis, M. Manger, A.H.Zewail, A. Douhal, I. Garcia-Ochoa, and A.D.H. Ayuso, Femtosecond dynamics of double proton transfer in a model DNA base pair: 7-azaindole dimers in the condensed phase, J. Phys. Chem. A 103, 7419-7431 (1999).

[6] A. Shikanai, T. Deguchi, T. Sota, T. Kuroda, A. Tackeuchi, S. Chichibu, and S. Nakamura, A pump and probe study of photoinduced internal field screening dynamics in an AlGaN/GaN single-quantum-well structure, Appl. Phys. Lett. 76, 454-456 (2000).

[7] A. Dubietis, G. Tamošauskas, R. Šuminas, V. Jukna, and A. Couairon, Ultrafast supercontinuum generation in bulk condensed media, Lith. J. Phys. 57, 113-157 (2017).

[8] A. Dubietis and A. Couairon, Ultrafast Supercontinuum Generation in Transparent Solid State Media (Springer Nature, Cham, Switzerland, 2019).

[9] A. Brodeur and S.L. Chin, Band-gap dependence of the ultrafast white-light continuum, Phys. Rev. Lett. 80, 4406-4409 (1998).

[10]M. Kolesik, G. Katona, J.V. Moloney, and E.M. Wright, Physical factors limiting the spectral extent and band gap dependence of supercontinuum generation, Phys. Rev. Lett. 91, 043905 (2003).

[11]C. Nagura, A. Suda, H. Kawano, M. Obara, and K. Midorikawa, Generation and characterization of ultrafast white-light continuum in condensed media, Appl. Opt. 41, 3735-3742 (2002).

[12]R. Huber, H. Satzger, W. Zinth, and J. Wachtveitl, Non-collinear optical parametric amplifiers with output parameters improved by the applications of a white light continuum generated in $\mathrm{CaF}_{2}$, Opt. Commun. 194, 443-448 (2001).

[13] P. Tzankov, I. Buchvarov, and T. Fiebig, Broadband optical parametric amplification in the near UVVIS, Opt. Commun. 203, 107-113 (2002).

[14]A.K. Dharmadhikari, F.A. Rajgara, N.C.S. Reddy, A.S. Sandhu, and D. Mathur, Highly efficient white light generation from barium fluoride, Opt. Express 12, 695-700 (2004).

[15]S.V.Chekalin, A.E. Dormidonov, V.O. Kompanets, E.D. Zaloznaya, and V.P. Kandidov, Light bullet super-continuum, J. Opt. Soc. Am. B 36, A43A53 (2019).

[16]M. Bradler, P. Baum, and E. Riedle, Femtosecond continuum generation in bulk laser host materials with sub- $\mu$ J pump pulses, Appl. Phys. B 97, 561-574 (2009).

[17]M. Bradler and E. Riedle, Sub-20 fs $\mu$ J-energy pulses tunable down to the near-UV from a $1 \mathrm{MHz}$ Yb-fiber laser system, Opt. Lett. 39, 2588-2591 (2014).

[18]R. Grigutis, G. Tamošauskas, V. Jukna, A. Risos, and A. Dubietis, Supercontinuum generation and optical damage of sapphire and YAG at high repetition rates, Opt. Lett. 45, 4507-4510 (2020).

[19]J. Kohl-Landgraf, J.-E. Nimsch, and J. Wachtveitl, $\mathrm{LiF}$, an underestimated supercontinuum source in femtosecond transient absorption spectroscopy, Opt. Express 21, 17060-17065 (2013).

[20]N. Garejev, G. Tamošauskas, and A. Dubietis, Comparative study of multioctave supercontinuum generation in fused silica, YAG, and $\mathrm{LiF}$ in the range of anomalous group velocity dispersion, J. Opt. Soc. Am. B 34, 88-94 (2017).

[21]J. Wang, Y. Zhang, H. Shen, Y. Jiang, and Z. Wang, Spectral stability of supercontinuum generation in condensed mediums, Opt. Eng. 56, 076107 (2017).

[22]S.A. Payne, L.K. Smith, R.J. Beach, B.H.T. Chai, J.H. Tassano, L.D. DeLoach, W.L. Kway, R.W. Solarz, and W.F. Krupke, Properties of Cr:LiSrAIF6 crystals for laser operation, Appl. Opt. 33, 55265536 (1994).

[23]D. Kopf, A. Prasad, G. Zhang, M. Moser, and U. Keller, Broadly tunable femtosecond Cr:LiSAF laser, Opt. Lett. 22, 621-623 (1997).

[24]C.D. Marshall, J.A. Speth, S.A. Payne, W.F. Krupke, G.J. Quarles, V. Castillo, and B.H.T. Chai, Ultraviolet laser emission properties of $\mathrm{Ce}^{3+}$ doped $\mathrm{LiSrAlF}_{6}$ and $\mathrm{LiCaAlF}_{6}$, J. Opt. Soc. Am. B 11, 2054-2065 (1994).

[25]M.V. Luong, M.J.F. Empizo, M. Cadatal-Raduban, R. Arita, Y. Minami, T. Shimizu, N. Sarukura, H. Azechi, M.H. Pham, H.D. Nguyen, Y. Kawazoe, K.G. Steenbergen, and P. Schwerdtferger, Firstprinciples calculations of electronic and optical properties of $\mathrm{LiCaAlF}_{6}$ and $\mathrm{LiSrAlF}_{6}$ crystals 
as VUV to UV solid-state laser materials, Opt. Mater. 65, 15-20 (2017).

[26]K. Shimamura, S.L. Baldochi, N. Mujilatu, K. Nakano, Z. Liu, N. Sarukura, and T. Fukuda, Growth of Ce-doped $\mathrm{LiCaAlF}_{6}$ and LiSrAlF 6 single crystals by the Czochralski technique under $\mathrm{CF}_{4}$ atmosphere, J. Cryst. Gowth 211, 302-307 (2000).

[27]M. Richardson, M.J. Soileau, P. Beaud, R. DeSalvo, S. Garnov, D.J. Hagan, S. Klimentov, K. Richadson, M. Sheik-Bahae, A.A. Said, E. Van Stryland, and B.H.T. Coi, Self-focusing and optical damage in Cr:LiSAF and Cr:LiCAF, Proc. SPIE 1848, 392-402 (1992).

[28]N.S. Shcheblanov, M.E. Povarnitsyn, P.N. Terekhin, S. Guizard, and A. Couairon, Nonlinear photoionization of transparent solids: A nonperturbative theory obeying selection rules, Phys. Rev. A 96, 063410 (2017).

[29]A. Kaiser, B. Rethfeld, M. Vicanek, and G. Simon, Microscopic processes in dielectrics under irradiation by subpicosecond laser pulses, Phys. Rev. B 61, 11437-11450 (2000).

[30]E. Migal, E. Mareev, E. Smetanina, G. Duchateau, and F. Potemkin, Role of wavelength in photocarrier absorption and plasma formation threshold under excitation of dielectrics by high-intensity laser field tunable from visible to mid-IR, Sci. Rep. 10, 14007 (2020).

\title{
LiSAF: EFEKTYVI IR PATVARI MEDŽIAGA SUPERKONTINUUMUI GENERUOTI ULTRAVIOLETINĖJE SPEKTRO SRITYJE
}

\author{
A. Šuminienè, V. Jukna, R. Šuminas, G. Tamošauskas, M. Vengris, A. Dubietis \\ Vilniaus universiteto Lazeriniu tyrimu centras, Vilnius, Lietuva
}

\section{Santrauka}

Eksperimentiškai ištirtas superkontinuumo generavimas nelegiruotame LiSAF kristale žadinant ultravioletiniais, regimaisiais ir infraraudonaisiais femtosekundiniais pirmosios ir antrosios Ti:safyro ir Yb:KGW lazerių harmonikų impulsais. Parodyta, kad naudojant infraraudonuosius žadinimo impulsus kristalo optine degradacija, pasireiškianti kaip laipsniškas superkontinuumo spektro siaurejjimas, prasideda daug sparčiau. Tai vyksta dèl smūginès jonizacijos, kuri didèja didèjant žadinimo bangos ilgiui. Patikimiausias veikimas stebètas naudojant trumpiausio bangos ilgio $(400 \mathrm{~nm})$ žadinimo impulsus (antroji Ti:safyro lazerio harmonika), kai LiSAF kristale generuojamas stabilus, beveik 1,3 optinès oktavos pločio superkontinuumo spektras su trumpabangiu nukirtimu ties $252 \mathrm{~nm}$, o netransliuojamas kristalas optiškai nedegraduoja vieną valandą esant $500 \mathrm{~Hz}$ impulsų pasikartojimo dažniui. 